\title{
Base Nacional Comum Curricular: \\ os discursos sobre a docência
}

Nacional Curriculum Common Core:

The discourses on teaching

Base Nacional Común Curricular:

los discursos sobre la docencia

\author{
NATHÁLIA FERNANDES EGITO ROCHA* \\ Universidade Federal da Paraíba, João Pessoa- PB. Brasil.
}

MARIA ZULEIDE DA COSTA PEREIRA**

Universidade Federal da Paraíba, João Pessoa- PB. Brasil.

\begin{abstract}
RESUMO: O presente texto tem por objetivo apresentar alguns dados investigativos a respeito das significações da docência que, em nossa análise, perpassaram o discurso da política da BNCC. A partir de um trabalho de doutorado, tomamos como base o entendimento de que a política da BNCC constrói um discurso normatizador e regulador, principalmente quanto à sua intencionalidade de alinhamento das políticas de avaliação, formação docente, material didático e outras à política curricular. No entanto, percebemos que embora a BNCC possa introduzir mudanças e efeitos na dimensão da prática e da organização da escola, ela não pode controlar a dinâmica e a singularidade do contexto da micropolítica.
\end{abstract}

Palavras-chave: Base Nacional Comum Curricular. Docência. Discurso.

\begin{abstract}
This paper aims to present some investigative data about the meanings of teaching that, in our analysis, go beyond the discourse of the policy of BNCC. Based on a doctorate thesis, we take
\end{abstract}

\footnotetext{
* Pedagoga, Mestre e Doutora em Educação pelo Programa de Pós-Graduação em Educação da Universidade Federal da Paraíba, na linha de pesquisa em Políticas Educacionais. E-mail: <nathaliafernandesufpb@gmail.com>.

* Doutora em Educação pela Universidade Metodista de Piracicaba (2001). Pós-doutorado em Educação na UERJ (2008) Atualmente é professora Titular da Universidade Federal da Paraíba atuando na graduação e pós-graduação. É fundadora do Grupo de Estudos e Pesquisas em Políticas Curriculares.
} 
as a basis the understanding that BNCC's policy builds a normative and regulatory discourse, mainly regarding its intentionality of alignment of evaluation policies, teacher training, didactic material and others to curricular policy. However, we realize that while BNCC can introduce changes and effects in the dimension of school practice and organization, it cannot control the dynamics and uniqueness of the micropolitical context.

Keywords: National Curriculum Common Core. Teaching. Discourses.

RESUMEN: Este documento tiene como objetivo presentar algunos datos investigativos sobre los significados de docencia que, de acuerdo con nuestro análisis, impregnaron el discurso de la política de la BNCC. A partir de un trabajo doctoral, nos basamos en el entendimiento de que la política de BNCC construye un discurso normativo y regulador, especialmente con respecto a su intencionalidad de alineamiento de las políticas de evaluación, capacitación docente, material didáctico y otras, a la política curricular. Sin embargo, se nota que, si bien la BNCC puede introducir cambios y efectos en la dimensión de la práctica y de la organización de la escuela, no puede controlar la dinámica y la singularidad del contexto de la micropolítica.

Palabras clave: Base Nacional Común Curricular. Docencia. Discurso.

\section{Introdução}

história da educação mostrou as inúmeras disputas e intencionalidades sobre
o conhecimento escolar e o papel docente empreendidas ao longo dos anos. É
nessa direção que, na atualidade, torna-se inadiável refletir sobre o complexo e contraditório contexto de aprovação da BNCC para a educação infantil e o ensino fundamental e os desdobramentos da base curricular para o ensino médio.

No processo de investigação do currículo e suas interfaces na contemporaneidade, trabalho este que, enquanto grupo de pesquisa, temos desenvolvido nos últimos quinze anos, buscamos trilhar analiticamente pela trajetória da BNCC através de um trabalho de doutorado em Educação.

Este trabalho nos possibilitou identificar arenas de influências, de onde se processaram inúmeras lutas pelos significados da política curricular; no processo de produção dos textos da BNCC, os constantes embates, contradições e interesses; as diferentes leituras 
elaboradas pelos docentes do contexto da prática sobre a política curricular e as problematizações em torno dos efeitos que a política curricular pode produzir.

Através dessas investigações percebemos que a tessitura da política curricular, bem como os projetos e iniciativas que a fundamentaram anteriormente, enfrentou inúmeras resistências, sobretudo considerando a crítica das entidades acadêmicas e de pesquisa da educação, as quais argumentavam principalmente sobre o afastamento docente do exercício político pedagógico e das possíveis perdas de espaço de decisão curricular, mediadas pelas singularidades dos contextos em que estão inseridos.

Sendo assim, com base no estudo desenvolvido por nós, partimos das análises de Stephen Ball (1989; 1994; 2016) e admitimos o impacto das influências externas na micropolítica da escola, mas, nos desviamos da ideia de que elas exercem poder absoluto nesses espaços. Pois os contextos da prática, em nosso caso, a escola, são sempre complexos e contingentes.

Por outro lado, concebendo o discurso como prática social, carregado ideologicamente e mediado pelo poder (FAIRCLOUGH, 2011). Assim, conforme este autor, o vemos como um modo de ação e como um produtor de efeitos (BALL; BOWE; GOLD, 1994).

Tomamos como base o entendimento de que a política da BNCC constrói um discurso normatizador e regulador, principalmente quanto à sua intencionalidade de alinhamento das políticas de avaliação, formação docente, material didático e outras à política curricular (BRASIL, 2017).

Neste texto iremos apresentar alguns dados investigativos a respeito das significações da docência que, em nossa análise, perpassam o discurso da política da BNCC e de que forma elas são interpretadas, contestadas ou aceitas pelos docentes das escolas.

Os eixos do referencial teórico adotado por nós versaram sobre questões que transitaram entre os estudos das políticas educacionais, o currículo escolar e a docência. Defendemos a ideia de Stephen Ball $(1994 ; 2016)$ sobre política, concebendo-a como um processo diverso e contestado, sujeito a múltiplas interpretações conforme é encenado.

Essa compreensão pressupõe considerar que não entendemos que a política curricular da BNCC será implantada nas escolas, mas que seu desenvolvimento se dará de forma criativa e complexa, embora limitada pelas possibilidades do discurso normatizador (BALL et al, 2016).

A política da BNCC tem a potencialidade de atribuir significações à docência que, inclusive, podem ser repercutidas na organização do trabalho pedagógico. No entanto, as respostas à política curricular serão sempre mediadas pelos atores da prática, considerando suas culturas, condições de trabalho, historicidade, interesses etc.

Se de um lado concordamos que as políticas podem criar circunstâncias que reduzem as possibilidades para decisão (BALL et al, 1994) e que podem mudar as estratégias, as finalidades e os objetivos educacionais, por outro lado, assumimos a ideia de Ball et al. (2016) de que elas sempre serão só parte do trabalho docente. Por isso, buscamos dar 
relevo aos matizes diferenciais e aos aspectos singulares apresentados nas narrativas docentes sobre suas próprias identidades profissionais e como estes profissionais interpretam a BNCC.

Notamos que para analisar essa problemática, em termos de investigar os discursos da BNCC e os encaminhamentos nas escolas, fez-se necessário um referencial teórico que desse conta de conceber a política como texto e como discurso. Isto é, sendo concreta e materializada através da legislação educacional, dos livros didáticos etc., mas, também compreendidos como processos discursivos complexos e mediados pelos contextos (BALL et al., 2016).

Assim, os trabalhos de Stephen Ball $(1992,1994,2016)$ e de Fairclough (2001) nos subsidiaram na tarefa de análise documental e textual do discurso da BNCC, bem como os dados obtidos em grupos focais, através das narrativas docentes.

\section{As redes e os contextos do currículo}

Para Goodson (2005) e Popkewitz (1994), o currículo é uma construção social e sua história se relaciona aos processos de luta pelas intencionalidades e objetivos da escolarização. Em cada contexto e fase histórica, o currículo corporifica as significações que lhes são correspondentes. Por isso, é possível perceber ao longo do tempo a centralidade do currículo, no que diz respeito à organização do conhecimento escolar e seus vínculos com as políticas educacionais, sobretudo, em torno do que deveria ser considerado como conhecimento legítimo.

Por entender que a construção curricular não é papel exclusivo do Estado, mas, tem sua origem e desenvolvimento a partir da circularidade dos saberes do cotidiano escolar, e influências internas e externas, assumimos o currículo como redes discursivas de significação. A ideia defendida por Pereira (2009) considera a existência de um movimento constante de múltiplos sentidos em contextos diversos em torno das definições curriculares.

São chamadas de redes porque as pensamos como sistemas que se interpenetram no processo de construção do currículo, através de um fluxo dinâmico e complexo. Assim, são produzidos diferentes sentidos para o currículo, tanto no que diz respeito às macro normatizações das políticas curriculares quanto pela materialidade e criações nos micro espaços. Segundo a autora, essas normatizações podem ou não ser incorporadas na prática, pois esses espaços são sempre fluídos, contingentes, singulares e dinâmicos.

Contextualmente, analisamos a partir de Ball (2005) o surgimento de um "novo" paradigma de governo educacional, o qual articula questões políticas, econômicas, culturais, sociais etc. Nessas arenas, de onde emergem as lutas por essas significações atualmente, destacamos o "imaginário neoliberal" (BALL et al, 2014). O currículo e os pacotes curriculares advindos desses modelos são sujeitados gradativamente às normatividades estabelecidas pela economia. 
O autor explica que neste novo paradigma, forma-se um grupo heterogêneo, formado por governos e agentes nacionais, organismos internacionais como o Banco Mundial e a OCDE, consultores vinculados aos interesses empresariais etc. $\mathrm{O}$ argumento que fundamenta essa configuração tem contribuído para a concessão de espaços para os setores econômicos/ mercadológicos: é o da crise política do Estado e do público, e consequentemente, da escola.

O pressuposto disso é de que o modelo gerencial, por meio de pacotes de gestão, currículo, formação de professores e tecnologias baseadas na lógica da qualidade total e da eficiência podem solucionar problemas educacionais. Concordamos com Hypolito (2010), ao considerar que, desta maneira, são reduzidos os problemas educacionais a problemas técnico gerenciais.

É nesta marcha de onde surgem projetos e políticas de currículo nacional atrelados às políticas de avaliação e formação docente que abarcam, segundo Ball (2001), categorias de mercado (relação público privado e a abertura para os setores empresariais- mercadológicos), gestão (novas formas de gestão privada baseada no gerencialismo administrativo) e a performatividade (desempenho por resultados e mecanismo de controle e responsabilização docente).

Os efeitos disso, conforme a análise de Ball (2005), podem ser considerados no âmbito macro - novos papéis do Estado, isto é, mínimo sob a perspectiva de oferta de políticas públicas sociais e máximo no sentido da regulação. E no âmbito micro, surgem novas formas no plano das práticas e da organização do trabalho das escolas e nas subjetividades dos atores envolvidos em contextos locais.

Inserida nesse contexto, a política da BNCC incorpora em sua linguagem alguns sentidos que merecem ser ressaltados. A BNCC, desde sua primeira versão, nutre-se da ideia salvacionista da educação e os produtores do texto legislativo da política curricular buscaram, ao longo das três versões, relacionar termos como direitos de aprendizagem e qualidade às categorias de conhecimento, objetivos de aprendizagem e competências e habilidades.

Ressaltamos, no entanto, que a produção das três versões do documento não se deu de forma linear. Foram inúmeras disputas em torno dos interesses da política curricular - Grupos empresariais a exemplo do Movimento pela Base, instâncias acadêmicas e de pesquisa educacional como a Anped, Anfope, ABdC e Anpae, órgãos governamentais a exemplo do MEC, Consed e Undime, além de grupos como o Escola Sem Partido.

Entendemos que a BNCC se configura como uma proposta de currículo uniforme e burocratizada, a qual desconsidera as diferenças e se fundamenta em uma lógica verticalizada; incorpora a cultura da performatividade e nega o movimento curricular ao desassociar a política da prática. A política da BNCC desconsidera a escola como um lócus produtor e inventivo, restringindo o fazer curricular à dimensão didático-metodológica.

Ratificamos, no entanto, que mesmo que essas políticas possam exercer alguma espécie de poder através da produção de conhecimentos ou mudar as circunstâncias de 
trabalho mediante discursos dominadores do neoliberalismo e da globalização, eles não são a totalidade do que é desenvolvido nas escolas e do trabalho docente. Pois, a partir de Ball et al (1989) e Ball et al (1994), rejeitamos a ideia de adaptação de políticas, embora, consideremos que a escola, enquanto organização, não é independente do seu entorno.

Por outro lado, urge refletirmos sobre a possibilidade de construção de uma cultura curricular fundamentada no profissionalismo e na valorização docente e em oposição aos valores do gerencialismo e da performatividade, conforme defendida por Moreira (2013). Para isso, faz-se indispensável refletir e problematizar sobre a questão da docência e suas práticas nos cotidianos das escolas na atualidade. Pois concordamos com Moreira (2013), ao entender que somente a partir da ativa participação docente e dos demais profissionais da educação e a partir de uma concepção curricular que corresponda às experiências e expectativas desenvolvidas pelos docentes em contextos locais é que uma política curricular se legitima.

Do contrário, o trabalho docente reduz-se ao treinamento de competências, e suas identidades profissionais continuam a ser tensionadas mediante processos regulatórios do currículo, presos às classificações dos sistemas de avaliação. Assim, contraditoriamente, os docentes veem-se perdendo seus espaços de autonomia profissional, em virtude do jogo neoliberal, ao mesmo tempo em que não se limitam a executar os currículos prescritos.

Destacamos, assim, dois possíveis efeitos das políticas curriculares nos contextos locais. De um lado, presumimos, através dos estudos em que nos fundamentamos, que quanto mais as políticas de currículo são desassociadas da prática e das experiências vivenciadas pelos seus atores, menos possibilidade têm de ser acomodadas (BALL et al., 1994). Justamente por desconsiderarem o trabalho desenvolvido pelas escolas e negarem a participação, a reflexão e o debate coletivo, elas tendem a cair no esquecimento, como a exemplo dos Parâmetros Curriculares Nacionais.

Por outro lado, os rebatimentos na prática podem ser mais visíveis, dada a potência da governabilidade da política (BALL et al., 2012), mediante a produção de artefatos sociais e de formações discursivas. Os discursos persuasivos e as culturas internalizadas podem repercutir no trabalho nos processos identitários dos envolvidos na prática cotidiana das escolas.

Em outras palavras, conforme Formosinho (2009, p. 50), esses discursos, "carregados de teor pedagógico, ideológico, moral e político, impõem uma série de novas demandas às escolas e aos professores", produzindo implicações nas formas de gestão do trabalho escolar e nas representações da profissão docente.

Para Libâneo, Oliveira e Toschi (2012, p. 280), refletir sobre a profissão docente exige “levar em consideração as condições históricas, culturais, políticas e sociais em que a profissão é exercida". Bem como, é preciso pautar-se pela própria natureza da atividade docente (RAMALHO et al., 2014). 
É nessa direção que, refletindo sobre as qualidades profissionais do ensino, Contreras (2002) discute sobre o que considera como precarização do trabalho docente, isto é, a negação da profissionalização docente. Contreras (2002) e Berezinsk (2001) analisam que o professorado, sobretudo a partir do capitalismo, passou por um processo sucessivo e conflituoso de perda de controle e sentido sobre seu trabalho, perdendo autonomia.

No contexto que articula a formação docente e as políticas curriculares, percebemos as gritantes contradições entre projetos como a Base Curricular Nacional (BCN), que se fundamenta em princípios que versam sobre a formação e valorização do magistério, e a BNCC, que se baseia em um conjunto de competências. Embora pareçam semelhantes na nomenclatura, são antagônicos e conflitantes em suas intencionalidades.

Nesse sentido, a Anfope (2017), posicionando-se a respeito da BNCC, problematiza em torno da ameaça ao princípio da autonomia; o monitoramento e a regulação mediante as avaliações de larga escala; comprometimento da formação docente sujeitadas às demandas da BNCC; compras e vendas de materiais didáticos para formação continuada com base nos interesses de fundações privadas e empresariais; a concepção de competências, considerada pela instituição como um retrocesso e o desmembramento do ensino médio.

Analisar a política curricular e seus desdobramentos na docência exige, conforme Contreras (2002), considerar que a profissionalidade docente, em termos de decisão curricular, se dá, sobretudo, na relação direta com a autonomia. Por isso, resistir aos projetos e políticas performáticas e racionalistas de currículo, exige gestão democrática da escola, valorização do magistério, formação docente e condições de trabalho que possibilitem um fazer/pensar crítico e reflexivo, mediante o controle sobre os processos de ensino e aprendizagem.

\section{(Pre)textos da BNCC e os enunciados sobre a docência}

Alguns dados de nossas análises são frutos de uma pesquisa de campo no município de João Pessoa, Paraíba. Buscamos analisar como os processos micro políticos (os docentes) desafiavam as ordens do discurso da BNCC através de suas interpretações particulares.

E também, através do trabalho de Fairclough (2001), mediante sua proposta de tridimensionalidade, a qual propõe uma análise que se articula entre o linguístico, o discursivo e o político-ideológico-cultural, analisamos o texto da BNCC; e com Ball et al. $(1992,1994)$, analisamos a complexidade da trajetória da política curricular.

Interessamo-nos por investigar os discursos que circundam a política curricular da BNCC e as narrativas docentes, aproximamos a proposta de Norma Fairclough aos estudos de Ball (1992; 1994; 2016), pois ambos não desassociam o texto do contexto social e relacionam os processos micro e macro políticos. 
Iniciamos com a análise das práticas discursivas do texto da terceira versão da BNCC, abordando as suas três dimensões: interdiscursividade e intertextualidade manifesta; as cadeias intertextuais e a coerência (FAIRCLOUGH, 2001). Vimos que a força discurso da BNCC advém de sua legitimação normativa obrigatória. A proposição ideacional do discurso centra-se na pretensão de garantir os direitos de aprendizagem discentes através das aprendizagens legitimadas como essenciais. Logo, impera-se que os currículos das escolas sejam adaptados à política.

No que tange aos processos intertextuais, percebemos que o discurso da BNCC é marcado tanto pelos textos da legislação educacional, através da representação discursiva direta, buscando legitimar e validar as proposições da política a partir da autoridade legal (a qual é pouco confrontada), quanto pelos textos que não estão claramente demarcados, mediante o discurso indireto.

Neste último, o discurso da BNCC vale-se dos interesses e expectativas de organismos internacionais como a OCDE e Banco Mundial e grupos empresariais como o Movimento Pela Base. O texto apresenta enunciados que, contraditoriamente, defendem direitos de aprendizagem, articulados com competências advindas de interesses empresariais.

Entendendo que as políticas assumem diferentes significados em outros contextos, buscamos analisar o que pensam os professores sobre a BNCC. Percebemos que alguns professores continuam a desconhecer a política curricular, em termos de aprofundamento e clareza quanto às estratégias em torno da proposta. Vimos que algumas interpretações basearam-se em propagandas midiáticas ou reportagens de jornais, que interferiram nos processos de "consumo do texto" (FAIRCLOUGH, 2001).

Enfatizamos algumas interpretações em torno da BNCC. Identificamos a preocupação docente no que diz respeito ao trato das diferenças locais e os riscos que a padronização pode causar. Por outro lado, percebemos que para alguns professores a BNCC tem a potencialidade de mudar a prática, tendo em vista seu caráter normativo.

Para outros participantes, a política se configura como um instrumento de responsabilização e produtora de efeitos negativos ao trabalho docente, inclusive adoecimentos e frustrações pessoais. Destacamos também as narrativas que apostaram no anonimato da política, tendo em vista seu distanciamento da escola e, por último, a afirmação de que a BNCC é coerente por selecionar o que é essencial, sendo necessário repensar o sistema nacional de avaliação a partir da política de BNCC.

Os dados ratificam a ideia de que os textos da BNCC, como todo discurso político, carregam possibilidades e limitações e as suas interpretações serão disputadas e ambivalentes. Assim, enquanto discurso, a BNCC estará sempre em processos de contestação nos espaços escolares, podendo manifestar diversas consequências e implicações para a prática. Entendemos que o discurso sobre a BNCC comporta ordens diferenciadas de discurso, mas que interagem entre si. Ora reportam aos documentos oficiais, ora são contestados a partir das experiências cotidianas. 
Quanto aos "micros aspectos" associados da prática discursiva, procuramos identificar através do texto da BNCC quais são os elementos do texto que atribuíram sentido à docência e como eles foram representados na relação com o currículo, assumindo-se como sentidos ideacionais do discurso político.

O texto apresenta inúmeras orações categóricas, fortemente autoritárias. Além disso, os produtores do texto, ao fazer uso de metáforas constroem um discurso persuasivo. Tomamos como exemplo, no que se refere propriamente aos professores, a expressão "protagonista". Embora o termo aponte para a agência docente, ele refere-se à ação implementadora da política na prática, através do "currículo em ação".

Por outro lado, as aparições no texto dos verbos ser, dever e fazer são frequentes, as quais indicam demandas e formulam identidades profissionais. Vimos a partir de Fairclough (2001) que essa escolha textual frequentemente implica alguma forma de poder, seja no trabalho pedagógico ou nas decisões curriculares.

Partimos de Fairclough (2001), ao afirmar que as orações do texto da BNCC são combinações de significados ideacionais, identitários e relacionais e textuais. Com base nisso, notamos que, referente à dimensão ideacional, o texto político da BNCC raramente faz alusão ao professor enquanto produtor do ato pedagógico e educativo. As identidades, por sua vez, são forjadas dentro de uma lógica ambivalente, em que o professor é chamado de protagonista ao mesmo tempo em que sua função é limitada.

Além disso, destacamos como tema central do texto político o significado potencial (FAIRCLOUGH, 2001) da palavra competência. Percebemos que esta, ao longo do texto, tem estreita relação com um contexto mais amplo, advindo de demandas emergentes e globais. A ideia é que a transferência de tais competências pode garantir os direitos de aprendizagem discentes. O termo é uma palavra-chave do texto da BNCC, o qual para Fairclough (2001) tem significado cultural, político e ideológico e funciona como um modo de hegemonia e um foco de luta pelos objetivos educacionais.

Refletimos também a respeito da concepção de um currículo por competências e suas implicações. Trouxemos Macedo (2012), a qual afirma que, para essa concepção, o currículo reduz-se a um plano de atividades de ensino pelas quais a escola é responsável. Além disso, no texto político da BNCC, a significação de currículo élimitada à ideia de percurso, ignorando sua complexidade e dimensão política.

Observamos que a formação de crenças e conhecimento se dá, sobretudo, a partir da força e da legitimidade do discurso. Isto não quer dizer dar poder absoluto ao discurso, mas considerar a sua importância nos processos de mudanças nas estruturas sociais.

Neste sentido, destacamos a tendência da comodificação (FAIRCLOUGH, 2001) presente no texto da BNCC. Buscou-se argumentar no texto da BNCC que a proposta estava alinhada aos sistemas educacionais globais. Entendemos que esse "alinhamento" se configura, dentre outros dispositivos, através da definição das competências e habilidades consideradas essenciais. 
A partir de Fairclough (2001), entendemos que o conceito adotado tem implicações normativas, passivas e objetificadoras, tornando, assim, mais clara a associação entre o currículo e avaliação (MACEDO. 2012).

É, pois, neste contexto que o currículo incorpora a ideia da performance, influenciando o funcionamento da escola e as subjetividades docentes. Em outras palavras, a prática social (escola), na qual incluímos a docência e o currículo, a partir da tendência da comodificação, passa a ser centrada na lógica da performance, através da noção de competência.

Compreendemos que através do discurso é possível construir, reproduzir, contestar e reestruturar os sistemas de conhecimento e crença dos atores da prática social (FAIRCLOUGH, 2001). Identificamos escolhas textuais carregadas ideológica, cultural e politicamente.

Buscamos abordar e analisar como os intérpretes, isto é, os professores participantes da pesquisa, confrontam tais significações e valores do discurso da BNCC, bem como quais lexicalizações de significados atribuíam às suas identidades profissionais. Diferentes interpretações foram identificadas referentes a estas questões.

Identificamos que, para os participantes, o "protagonismo docente" foi invisibilizado. Alguns dos participantes justificaram que a BNCC não foi criada a partir de suas experiências e não consideram as latentes desigualdades sociais nas escolas brasileiras. Por outro lado, vêm a BNCC como mais um mecanismo de cobrança por resultados, considerando que este não é um aspecto exclusivo da BNCC, mas, ao contrário, já se expressa através de outras políticas e projetos desenvolvidos na escola. E, finalmente, apostam em melhores oportunidades formativas aos docentes que estão na escola.

Essas análises podem indicar perspectivas críticas sobre os efeitos e repercussões da política nos contextos locais. A princípio, identificamos que, na visão de alguns participantes, a BNCC proporcionará renovação à escola. Porém, há também a suspeita de que a BNCC exercerá cobranças, sem que haja mudanças efetivas nas condições de trabalho. Vimos igualmente que, de imediato, as repercussões da BNCC podem ser percebidas através das escolhas dos materiais didáticos, os quais já se encontram "adaptados" à proposta da política curricular.

Ainda que inseridas em complexos processos de interpretação, acomodação, traduções ou abstenção (BALL et al, 1994), as políticas curriculares, a exemplo da BNCC, propõem e sinalizam movimentos conflituosos na prática, a partir dos efeitos produzidos na disputa pelas finalidades, objetivos e estratégias pedagógicas e educativas.

Ao passo em que se determina e se legitima determinados saberes, competências e habilidades em detrimento de outras, essas normatividades curriculares buscam controlar o trabalho docente através de mecanismos de monitoramento e responsabilização.

Em se tratando da BNCC, é possível perceber efeitos de primeira ordem (BALL et al, 1994), a exemplo da alteração dos materiais didáticos; pauta central da BNCC nas 
formações continuadas e nos planejamentos pedagógicos. E os efeitos mais amplos, consequência dos primeiros, dizem respeito ao monitoramento do trabalho desenvolvido nas escolas. Na cultura e mediante a lógica da performatividade apresentada por Stephen Ball (2001), a subjetividade do docente e seu trabalho podem ser alterados, restringindo a sua autonomia e o trabalho coletivo democrático da escola.

Os discursos docentes em relação à BNCC passam a ser considerados, por um lado, como complementares à política, sobretudo quando considerada como inovação, e, por outro, como plataforma de lutas, nas quais há questionamento, reflexão e problematizações em torno dos sentidos da política curricular e de suas contradições no contexto da prática.

Em determinados momentos, percebemos que a proposta da BNCC agride a visão que os professores têm de si mesmos (BALL et al, 1994). Em vista disso, buscamos identificar como eles significam sua identidade a partir das próprias experiências. Analisamos que mesmo em um contexto de racionalização do trabalho docente, eles continuam a produzir maneiras singulares de ser e estar na profissão (NÓVOA, 1995).

Inspiradas na pesquisa de Nunez, Ramalho e Oliveira (2014), para a sistematização desses resultados, selecionamos os verbos, adjetivos e substantivos predominantes nas respostas dos participantes. Em uma das escolas, identificamos a predominância de verbos de ação, substantivos situados numa dimensão sócio-afetiva, cuja ideia de docência se baseia na visão de sacerdócio e vocação.

Enquanto na segunda escola, os verbos indicam representações docentes coesas à lógica da docência enquanto prática social vinculadas a uma perspectiva que concebe o processo de organização do trabalho pedagógica a partir da mediação e da troca de saberes e, além disso, destacam expressões que caracterizam a docência como profissão, sob o ângulo da esperança de transformação social.

A última escola cujas narrativas dos participantes foram analisadas atribui à docência, metaforicamente, uma concepção militante. Isto é, para eles, a identidade docente se fundamenta na luta em prol da educação, tendo por horizonte a ascensão social dos discentes.

Notamos que o legado da noção assistencialista e vocacionada de docência ainda é permanente no discurso dos docentes. Essa visão, que idealiza e relaciona a identidade docente a uma projeção de uma missão, com base numa ação heroica e sacrificadora, torna problemática a reflexão crítica da educação enquanto prática social.

Mas, em contrapartida, de modo geral, as significações sobre a docência foram definidas a partir da mediação do contexto mais amplo e das realidades locais, e quanto às decisões curriculares pautam-se na circularidade dos saberes da prática e nos conhecimentos pedagógicos.

Posto isto, fomos levados a indagar sobre o que pensam os docentes a respeito dos pilares em que a sua profissão se fundamenta. As respostas, em parte, foram similares às concepções de docência, destacando expressões como pesquisa, reflexão e compromisso. 
Mas, demos ênfase ao fato de o princípio da autonomia não ter sido mencionado pelos docentes. Para Nóvoa (1995), o processo identitário docente também perpassa pela capacidade de exercer com autonomia a atividade, pelo sentimento de controle do trabalho que se desenvolve Tendo em vista o caráter tutorial da proposta da BNCC, entendemos que a necessidade de se refletir e fortalecer o debate sobre a autonomia docente nas escolas e nas formações inicial e continuada de professores torna-se urgente.

Esses processos, por sua vez, exigem a participação e a valorização dos atores envolvidos. A participação, por sua vez, não está isenta de conflitos. Mas, ao contrário, pauta-se no diálogo e na negociação constantes das intencionalidades e dos interesses do ato pedagógico e das decisões curriculares. Assim, valores éticos, políticos e cidadãos, urgentes de serem valorizados na escola atualmente, fogem à possibilidade de uma descrição prévia e exterior à escola. Pois, o ato pedagógico pressupõe contextualização e reflexão cotidiana.

\section{Últimas considerações}

Entendemos que a BNCC pode introduzir mudanças não apenas na dimensão da sala de aula, mas no plano das organizações da escola e dos currículos. No entanto, a partir das nossas análises, percebemos que os docentes desafiam as ordens do discurso da BNCC, em termos de se posicionarem reflexivo e politicamente sobre suas identidades profissionais. Assim, percebemos que eles rejeitam a noção técnica da profissão, no sentido de reproduzir ou cumprir planos de ação estabelecidos exterior e contraditoriamente às suas realidades e práticas.

Nosso interesse por identificar e analisar diferentes maneiras de abordar essas definições relacionadas ao currículo indica que essas representações estarão em constante movimento e se configuram como fontes de conflitos na prática, no que diz respeito às ações, aos saberes e identidades profissionais dos professores.

Os enunciados da BNCC a respeito do processo de ensinar/aprender se empenham por tornar neutras as dimensões complexas que contextualizam esse ato. A retórica da Base, através de sua proposição normatizadora de currículo e seu "alinhamento" com outras políticas associadas e correspondentes, "simplifica" esse processo e desconsidera a importância dos processos, ao maximizar o valor dos resultados.

Ao contrário, partimos do entendimento de que a docência se faz pelo contínuo diálogo e reflexão com a atividade a que se empenha. Essa prática, assim como entendemos as redes discursivas de significação do currículo, se dá na integração de saberes, de influências e proposições mútuas e conflitantes.

Apesar de reconhecermos que a BNCC projeta identidades performáticas nos docentes, tanto no que diz respeito à retórica quanto às estratégias da política, essas identidades não se reduzem a isso. Diversa e simultaneamente, são construídas no cotidiano da escola 
e em suas ações, como também a partir das histórias particulares e esperanças dos atores da prática.

Ao supervalorizar a apropriação das competências e habilidades, políticas educacionais como a BNCC diminuem os destinos e valores educativos. Com base em Franco (2012), vemos que, através dessa lógica, a prática pedagógica assume o papel de apenas racionalizar ações para qualificar a eficiência do ensino a partir de uma perspectiva instrumental.

Os reflexos disso podem ser percebidos no plano da formação docente. Ela, por sua vez, "vai significando cada vez mais a preparação metodológica do professor e cada vez menos um campo de investigação sistemática da realidade educativa" (LIBÂNEO, 1998, p. 126 apud FRANCO, 2012, p. 167).

A proposta de Base Nacional Comum para Formação de Professores, anunciada no final do ano de 2018 pelo MEC, pode ser um exemplo disso. Um grupo de entidades acadêmicas e educacionais ${ }^{1}$ publicou uma nota a respeito da política, denunciando mais uma proposta imposta sem debate. O grupo questiona a necessidade de nova diretriz para a formação de formação, argumentando sobre a existência das Diretrizes Curriculares Nacionais de 2016, a qual foi aprovada pelo CNE, com amplo debate da sociedade.

Essa nova BNC-Professores, segundo informações disponibilizadas pelo MEC, baseia-se em três eixos norteadores da formação inicial e continuada dos docentes: conhecimento, prática e engajamento. Além disso, são previstas mudanças no tempo de formação e a BNCC é tomada como referência dessas ações.

Cabe-nos destacar que se a formação de professores não estiver vinculada a uma "intencionalidade, a uma política, a uma epistemologia, a pesquisas aprofundadas dos saberes pedagógicos", ela pode "caracterizar uma concepção extremante pragmatista, reprodutivista, tecnista da ação docente" (FRANCO, 2012, p. 167). Esse é um quadro que exige contínua reflexão e criticidade. Os efeitos de uma política educacional, curricular ou para formação de professores não estão postos nem podem ser controlados pelos textos e legisladores. Eles repercutem nas práticas, nos cotidianos e nas relações interpessoais. E, por isso, análises que se empenhem em investigar, refletir e problematizar sobre as trajetórias e rumos dessas políticas tornam-se cada vez mais necessárias.

Entendemos que as referências curriculares devem ser assumidas enquanto esboço para as ações desenvolvidas nos cotidianos escolares. Defendemos que tais projetos sejam construídos tomando como centro os atores da prática - os professores, os quais devem, de forma efetiva, desenvolver e refletir sobre os processos educativos e consequentemente, pedagógicos, a partir de seus contextos particulares.

Recebido em: 29/06/2019 e aprovado em: 11/06/2019 


\section{Notas}

1 Associação Nacional de Pós-Graduação e Pesquisa em Educação (ANPEd), Associação Brasileira de Currículo (ABdC), Associação Brasileira de Ensino de Biologia (SBEnBIO), Associação Nacional de Pesquisa em Financiamento da Educação (FINEDUCA), Associação Nacional de Política e Administração da Educação (ANPAE), Associação Nacional pela Formação dos Profissionais da Educação (ANFOPE), Centro de Estudos Educação e Sociedade (CEDES), Fórum Nacional de Diretores de Faculdades, Centros de Educação ou Equivalentes das Universidades Públicas Brasileiras (FORUMDIR), Movimento Nacional em Defesa do Ensino Médio (MNDEM).

\section{Referências}

BALL, Stephen J. Educational reform: a critical and post-structural approach. Buckingham: Open University Press, 1994.

BALL, Stephen J. Profissionalismo, gerencialismo e performatividade. Cadernos de Pesquisa, São Paulo, v. 35, n. 126, p. 539-564, set./dez. 2005.

BALL, Stephen J.; MAGUIRE, Meg; BRAUN, Annette. Como as escolas fazem as políticas: atuação em escolas secundárias. Tradução de Janete Bridon. Ponta Grossa: Editora UEPG, 2016.

BALL, Stephen. J. La Micropolítica de la escuela. Madrid: Paidós; MEC, 1989.

BOWE, R.; BALL, S.; GOLD, A. Reforming education \& changing schools: case studies in policy sociology. London: Routledge, 1992.

BRASIL. Base Nacional Comum Curricular (BNCC). Educação é a Base. Brasília, MEC/CONSED/ UNDIME, 2017. Disponível em: <http://basenacionalcomum.mec.gov.br/images/BNCC_publicacao. pdf>. Acesso em: 19 dez. 2018.

BRZEZINSKI, I. Pedagogia, pedagogos e formação de professores: busca e movimento. Campinas: Papirus, 1996.

CONTRERAS, José. A autonomia de professores. São Paulo: Cortez, 2002.

CORAZZA, Sandra Mara. Diferença pura de um pós currículo. In: LOPES, Casimiro (Orgs.).

Currículo: debates contemporâneos. São Paulo: Cortez, 2005, p. 103-114.

FAIRCLOUGH, Norman. Discurso e mudança social. Brasília: Editora UNB, 2001.

FORMOSINHO, J. Formação de professores: Aprendizagem profissional e ação docente. Porto, Portugal: Ed. Porto, 2009.

FOUCAULT, M. A Arqueologia do saber. Rio de Janeiro: Forense, 1986.

FRANCO, Maria Amélia SANTORO. Pedagogia e prática docente. São Paulo: Cortez, 2012

GOODSON, I. F. Currículo de Aprendizagem e Política de Vida. Londres e Nova York: Routledge, 2005.

GOODSON, I. F. Currículo: Teoria e História. Petrópolis: Vozes, 1995. 
HYPÓLITO, A. M. Políticas curriculares, estado e regulação. Educação \& Sociedade, Campinas, São Paulo, v. 31, n. 113, p. 1337-1354, out./dez. 2010.

LIBÂNEO, José Calos; OLIVEIRA, João FERREIRA DE; TOSCHI, Mirza SEABRA. Educação escolar: políticas, estrutura e organização. 10. ed. São Paulo: Cortez, 2012. (Coleção Docência em Formação).

MACEDO, Elizabeth. Currículos: debates contemporâneos. São Paulo: Cortez, 2002.

MOREIRA, Antônio Flávio BARBOSA. Em busca da autonomia docente nas práticas curriculares no Brasil. In: OLIVEIRA, Maria Rita N. S e PACHECO, José Augusto. Currículo, Didática e Formação de Professores. 1 ed. Campinas, SP. Papirus, 2013.

NÓVOA, Antônio (Coord.). Os professores e a sua formação. 2ํe․ edisboa: Dom Quixote, 1995.

PEREIRA, Maria Zuleide DA COSTA. A Centralidade da pluralidade Cultural nos debates contemporâneos. Currículo sem Fronteiras, Rio de Janeiro, v. 9, N. 2, 169-184, dezembro, 2009.

POPKEWITZ, T. S. História do Currículo, Regulação Social e Poder. In: T. T. Silva (org.). O sujeito da educação: estudos foucaultianos. 6. ed. Petrópolis: Vozes, p. 173-210, 1994.

RAMALHO, Betânia LEITE e NUÑEZ, Isauro BELTRÁN. Formação, representações e saberes docente: elementos para se pensar a profissionalização dos professores. Campinas: Mercado de Letras; Natal: UFRN 2014. 